Marquette University

e-Publications@Marquette

Biological Sciences Faculty Research and

Publications

Biological Sciences, Department of

$8-1-2005$

\title{
A Mechanistic Explanation for Global Patterns of Liana Abundance and Distribution
}

Stefan A. Schnitzer

Marquette University, stefan.schnitzer@marquette.edu

Published version. The American Naturalist, Vol. 166, No. 2 (August, 2005): 262-276. DOI. (C) 2005 University of Chicago Press. Used with permission.

Stefan Schnitzer was affiliated with the University of Wisconsin - Milwaukee at the time of publication. 


\title{
A Mechanistic Explanation for Global Patterns of Liana Abundance and Distribution
}

\author{
Stefan A. Schnitzer
}

Department of Biological Sciences, University of WisconsinMilwaukee, Milwaukee, Wisconsin 53211

Submitted November 9, 2004; Accepted March 23, 2005; Electronically published May 16, 2005

Aвstract: One of the main goals in ecology is determining the mechanisms that control the abundance and distribution of organisms. Using data from 69 tropical forests worldwide, I demonstrate that liana (woody vine) abundance is correlated negatively with mean annual precipitation and positively with seasonality, a pattern precisely the opposite of most other plant types. I propose a general mechanistic hypothesis integrating both ecological and ecophysiological approaches to explain this pattern. Specifically, the deep root and efficient vascular systems of lianas enable them to suffer less water stress during seasonal droughts while many competitors are dormant, giving lianas a competitive advantage during the dry season. Testing this hypothesis in central Panama, I found that lianas grew approximately seven times more in height than did trees during the dry season but only twice as much during the wet season. Over time, this dry season advantage may allow lianas to increase in abundance in seasonal forests. In aseasonal wet forests, however, lianas gain no such advantage because competing plants are rarely limited by water. I extend this theory to account for the local, within-forest increase in liana abundance in response to disturbance as well as the conspicuous decrease in liana abundance at high latitudes.

Keywords: climbers, latitudinal gradient, lianas, plant distribution, seasonality, tropical forests.

Documenting patterns of the abundance and distribution of organisms and developing theories to explain these patterns are central to the study of ecology. Some large-scale ecological patterns, such as the increase in biological diversity with decreasing latitude, are extremely well documented (reviewed by Willig et al. 2003). Other patterns, however, such as the increase in the abundance of most organisms throughout the tropics with annual rainfall, are

\footnotetext{
* E-mail: schnitze@uwm.edu.
}

Am. Nat. 2005. Vol. 166, pp. 262-276. (C) 2005 by The University of Chicago. 0003-0147/2005/16602-40731\$15.00. All rights reserved. equally intriguing but have received less attention (Gentry 1982, 1995; Clinebell et al. 1995). In both cases, the mechanisms responsible for these large-scale patterns remain elusive. Comprehensive explanations for patterns of species abundance at various spatial scales require theories that incorporate mechanisms that operate over these spatial scales. Development of these theories, however, may require the integration of multiple disciplines, which may provide a better explanation for the abundance and distribution of organisms than any single approach.

Because mechanistic explanations for the abundance and distribution of most organisms have proven difficult to develop, an alternative approach is to focus on exceptional groups of species whose patterns of abundance and distribution deviate from other groups. Determining the mechanisms that control the exceptional distribution of some groups of species may help explain the more common distribution patterns. For example, in tropical forests, the density of most vascular plant groups (e.g., trees, palms, herbs, and epiphytes) increases with increasing precipitation (Gentry 1982, 1995; Clinebell et al. 1995; Dattaraja and Sukumar 2004). In contrast, the abundance of lianas (woody vines), a key component of most tropical forests (Schnitzer and Bongers 2002; Pérez-Salicrup et al. 2004), may be invariable or even vary negatively with annual precipitation. Gentry $(1991,1995)$ speculated that lianas vary more with the seasonality of rainfall, peaking in tropical moist forests with a strong seasonal drought but moderate rainfall compared with tropical wet and dry forests. If Gentry's speculations are correct, the mechanisms that control the abundance of lianas likely differ from those of other plant types. These mechanisms, however, remain poorly understood.

In addition to using lianas as a means to understanding the distribution of other growth forms, providing a mechanistic explanation for the abundance of lianas themselves is essential for a basic understanding of the ecology of tropical forests (Putz and Mooney 1991; Schnitzer and Bongers 2002; Pérez-Salicrup et al. 2004). Lianas are extremely abundant in and add considerably to the architectural complexity of most tropical forests, constituting 
between $10 \%$ and $45 \%$ of the woody individuals and ranking second in biomass only to trees (Putz 1983; Gentry 1991; DeWalt and Chave 2004). Lianas also have a large impact on many forest processes by reducing tree growth and fecundity, suppressing gap phase regeneration, and altering whole-forest carbon sequestration and water budgets (Putz 1984; Stevens 1987; Schnitzer and Carson 2000, 2001; Schnitzer et al. 2000, 2004; Laurance et al. 2001; Pérez-Salicrup 2001; Andrade et al., forthcoming). Furthermore, lianas may be increasing in abundance throughout the Neotropics (Phillips et al. 2002; Wright et al. 2004), a phenomenon that could have significant implications for the regeneration and dynamics of tropical forests. Because lianas can effectively displace trees when found in high densities (e.g., Schnitzer et al. 2000; Laurance et al. 2001), the increase in liana abundance may further reduce tree growth and alter tree species composition, thus fundamentally changing the physiognomy of these forests and reducing the capacity of forests to sequester atmospheric carbon (Putz 1984; Schnitzer et al. 2000; Phillips et al. 2002; Schnitzer and Bongers 2002). Determining the mechanisms responsible for the proliferation of lianas is therefore critical for predicting the impacts of lianas on forests as climatic factors and land use practices continue to change.

In this study, I use two independent data sets that vary in spatial scale to determine the biogeographical patterns of liana abundance with respect to mean annual precipitation and seasonality of rainfall. After establishing these patterns, I then propose a simple and general theory based on the combination of ecological and ecophysiological principles to explain the predominant mechanism responsible for the pantropical patterns of liana abundance. I support this theory with several distinct lines of empirical evidence from both novel data and previously published studies. This theory also provides the framework in which to describe the mechanisms that control liana abundance at a local scale (the clumped distribution of lianas within a forest; Putz 1984; Pérez-Salicrup et al. 2001; Schnitzer et al. 2000) and the sharp decrease in liana abundance with increasing latitude (Gentry 1982, 1991; Ewers et al. 1991).

\section{Testing the Patterns of Liana Abundance}

I examined the abundance of lianas with respect to forest seasonality and total annual rainfall at both the regional and pantropical scales. At the regional scale, I censused the number of liana stems in three lowland forests $(<200$ $\mathrm{m}$ elevation) along a strong rainfall and seasonality gradient across the relatively narrow $(55 \mathrm{~km})$ isthmus of Panama. In each forest, I quantified the number and basal area (measured $130 \mathrm{~cm}$ from the roots) of all free-standing and climbing lianas $\geq 0.2 \mathrm{~cm}$ in diameter that were rooted in randomly selected replicated plots located in intact forest. I included only independently growing stems that were not connected aboveground to any other stem in the census (apparent genets; sensu Mascaro et al. 2004).

The forests included Fort Sherman $\left(9^{\circ} 21^{\prime} \mathrm{N}, 79^{\circ} 57^{\prime} \mathrm{W}\right)$, a tropical wet forest; Barro Colorado Island (BCI), Panama $\left(9^{\circ} 9^{\prime} \mathrm{N}, 79^{\circ} 50^{\prime} \mathrm{W}\right)$, a seasonally deciduous tropical moist forest; and Cocoli $\left(8^{\circ} 58^{\prime} \mathrm{N}, 79^{\circ} 34^{\prime} \mathrm{W}\right)$, a tropical dry forest (classified using the Holdridge system of forest classification; Holdridge 1967). The seasonality and mean annual rainfall of each forest was estimated using data that have been collected monthly for $>20$ years at or near each site by the Meteorology and Hydrology Branch, Panama Canal Authority, Republic of Panama. Fort Sherman is located on the Atlantic coast of Panama and receives $>3,000 \mathrm{~mm}$ mean annual rainfall (on the basis of 94 years of data). The tropical moist forest of BCI is located in central Panama and receives approximately 2,600 $\mathrm{mm}$ mean annual rainfall (72 years of data). Cocoli is located on the Pacific side of Panama and receives approximately $1,750 \mathrm{~mm}$ mean annual rainfall (20 years of data; see also Condit et al. 2000). Each of these forests experiences a seasonal reduction in rainfall (dry season), which commonly lasts 34 months from mid-December through mid-April (Leigh 1999; Condit et al. 2000, 2004). Of the three forests, Fort Sherman has the least severe dry season, which lasts approximately 106 days. The dry season is longer on BCI, lasting approximately 118 days, and BCI receives around $10 \%$ less rain during the dry season than Fort Sherman over a comparable period of time. Cocoli has the longest and most severe dry season, which is approximately 129 days long, and Cocoli receives approximately half as much dry season rainfall as BCI over a comparable period (Condit et al. 2004). Concordant with the severity of the dry season, the leaf density of the canopy declines by approximately $3 \%, 10 \%$, and $19 \%$ during the dry season relative to the wet season at Fort Sherman, BCI, and Cocoli, respectively (Condit et al. 2000). There is some overlap in tree species among the sites; however, the percentage of canopy species that are deciduous differs substantially, with $14 \%, 28 \%$, and $41 \%$ of the species being seasonally deciduous at Fort Sherman, BCI, and Cocoli, respectively (Condit et al. 2000).

Apart from differences in rainfall, other important climatic conditions are similar in all three forests. Each forest is mostly evergreen, and each experiences mean monthly temperatures of around $27^{\circ} \mathrm{C}$ throughout the year, typical of lowland tropical forest (Condit et al. 2000, 2004). The forests have somewhat different histories, with the BCI forest being the oldest and Cocoli the youngest. The BCI forest used in this study was actually a mix of old growth ( $>500$ years) located on BCI and mature secondary forest 
located on an adjacent mainland peninsula (Gigante Peninsula; described in Leigh 1999). The census plots in these two forests did not differ in liana abundance $(3,521 \pm$ $796 \mathrm{ha}^{-1}$ vs. $3,873 \pm 449 \mathrm{ha}^{-1}$ ), and thus the data were combined. The Fort Sherman forest appeared to have been free of severe disturbance for $>200$ years and has many large, slow-growing trees (Condit et al. 2004). The Cocoli forest is somewhat younger, estimated to be mature secondary forest around 120 years old (Condit et al. 2004). Although the abundance of lianas may be higher in very young secondary forests ( $<40$ years old), in Panama, forests older than 70 years do not appear to differ in liana abundance and diversity from forests $\sim 100$ and $>500$ years old (DeWalt et al. 2000), and thus forest age was probably not an important factor in this study. Replication within each forest consisted of eight and nine randomly selected $10 \times 10-\mathrm{m}$ plots $\left(100 \mathrm{~m}^{2}\right)$ at Cocoli and Fort Sherman, respectively, and 16 plots that were $24 \times 36 \mathrm{~m}\left(864 \mathrm{~m}^{2}\right)$ on BCI (eight) and Gigante Peninsula (eight). Although plot size and number differed among the sites, each site was censused at approximately the same time using identical methodologies.

To ascertain whether the patterns of liana abundance across the isthmus of Panama were consistent with patterns at the pantropical scale, I used a database that consisted of all lianas, trees, and shrubs $\geq 2.5 \mathrm{~cm}$ diameter in 0.1-ha plots from lowland tropical forests around the world (data collected by A. H. Gentry and summarized in Phillips and Miller 2002). The main advantages of using the Gentry data set are that it is well replicated and that the methodology was consistent among the sites, ensuring valid among-site comparisons. I restricted this data set to forests that were classified as tropical lowland dry, moist, or wet forests (on the basis of Holdridge 1967), had $\geq 500$ $\mathrm{mm}$ of rainfall annually, and were $\leq 1,000 \mathrm{~m}$ above sea level (sensu Dirzo 2001). Thus, I omitted forests that were classified as subtropical, montane, and premontane to reduce confounding the differences in latitude, elevation, and temperature among the sites. I also omitted the forests classified as "rain" forests because this category included only two sites that also met the other criteria.

In total, this data set included 66 tropical forests: 24 dry forests, 31 moist forests, and 11 wet forests from sites located in Africa (8), Asia (4), Central America (9), and South America (45). Each of these four major geographic locations included all three forest types, except the Asian forests, which did not contain dry forests. I tested whether liana abundance differed among the three forest types and the four geographic locations using ANOVA (SAS Institute 2000). Because the abundance of lianas did not differ significantly among the four geographic areas and there was no significant interaction between forest type and geographic location, I reanalyzed the model omitting geo- graphic location as a factor. I also examined the patterns of liana and tree abundance over a gradient of total annual precipitation using linear regression (SAS Institute 2000). I ran this analysis both with and without the site with the highest rainfall to test whether this one site disproportionately affected the analysis.

\section{Empirical Evidence for the Patterns of Liana Abundance}

Across the isthmus of Panama, liana abundance was highest in the tropical dry forest, which had nearly five times the number of lianas as the wet forest (fig. 1A). The abundance of lianas in the seasonal moist forest of BCI was slightly greater than in the wet forest of Fort Sherman, but this difference was not significant. Gentry's own data reflected the same pattern, with liana abundance significantly higher in the dry forests than either moist or wet forests $(P<.01, F=5.47, \mathrm{df}=2,63$; data not shown $)$. Liana basal area followed essentially the same pattern (fig. $1 B)$, demonstrating that the higher abundance of lianas in seasonally dry forests was not balanced by a comparable decrease in liana basal area.

Regressing liana abundance onto mean annual precipitation for the 65 pantropical sites further revealed the significant negative relationship between these two variables, consistent with the forest classifications (fig. 2). In contrast, tree and shrub abundance increased with precipitation over the 65 sites, demonstrating the contrasting patterns of abundance for lianas versus trees and shrubs (fig. 2). Analyzing the smaller paleotropical data set (Africa and Asia) revealed that the patterns of liana and tree abundance with mean annual precipitation in these paleotropical forests were similar to those of the larger pantropical data set (fig. 2; lianas: $P=.12, R^{2}=0.23, n=12$; trees: $\left.P=.07, R^{2}=0.29, n=12\right)$, although the lack of significance was probably due to the low sample size. Consequently, although the majority of the data were from the Neotropics, liana abundance also appears to decrease linearly with annual precipitation in the paleotropics.

The high abundance of lianas in forests with low precipitation and high seasonality is consistent with other studies. For example, in the "liana forests" of Brazil, which once covered approximately 100,000 km² of Amazonia, total annual rainfall is moderate $(\sim 1,750 \mathrm{~mm})$, but the dry season is very strong with very little precipitation (Balée and Campbell 1990; Gentry 1991). Likewise, lianas are also extraordinarily abundant and diverse in highly seasonal Bolivian forests on the rim of the Amazon basin, where lianas can compose over $80 \%$ of the woody individuals and $44 \%$ of the woody species that are in the canopy (Pérez-Salicrup et al. 2001). Lianas are also exceedingly abundant in moist and dry lowland forests of 

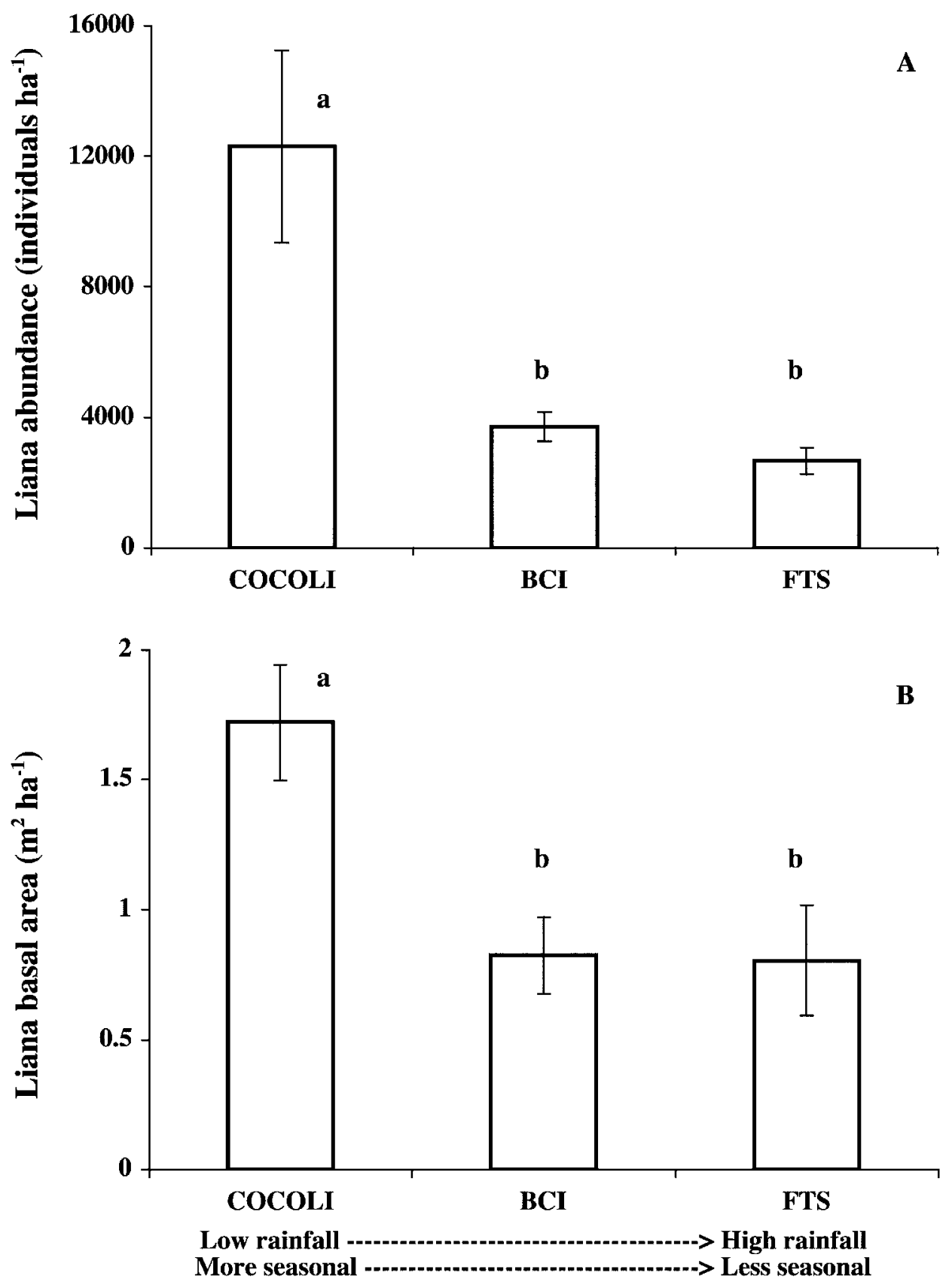

Figure 1: Abundance $(A)$ and basal area $(B)$ of lianas $(\geq 0.5 \mathrm{~cm}$ diameter) across the rainfall and seasonality gradient of the isthmus of Panama (means $\pm 1 \mathrm{SE}$ ). The three sites represent dry (Cocoli), moist (Barro Colorado Island [BCI]), and wet (Fort Sherman [FTS]) forests. Liana abundance and basal area were significantly higher in the dry forest of Cocoli compared with the moist and wet forests of BCI and FTS (liana abundance: $P<.0001, F=21.34, \mathrm{df}=2,30$; basal area: $P=.02, F=4.69, \mathrm{df}=2,30)$. BCI and FTS were not significantly different from one another in either abundance or basal area (Tukey HSD test). Both liana abundance and basal area were log transformed to normalize the residuals when necessary to meet the assumptions of normality and equal variance. Nontransformed data are presented. 


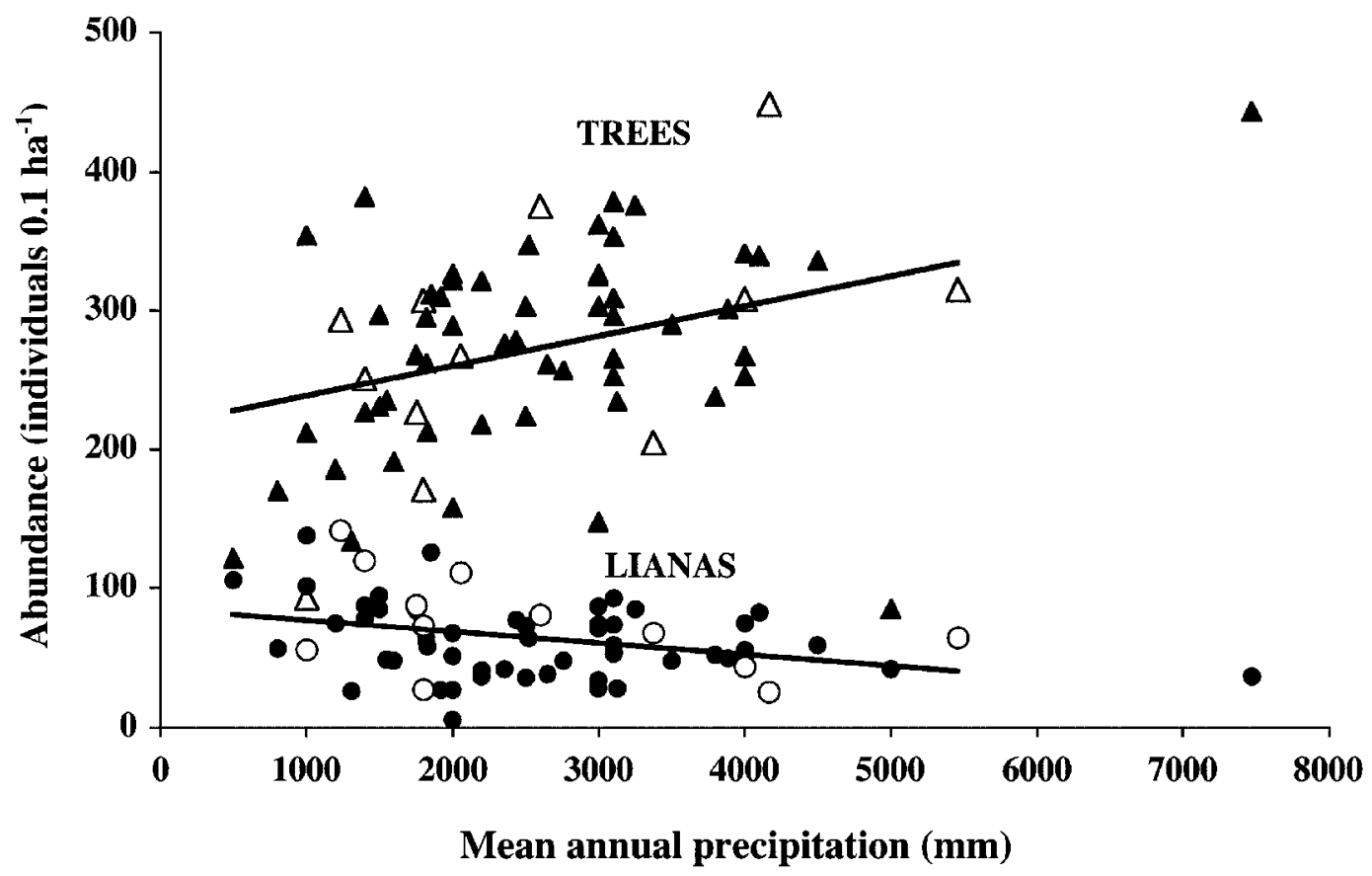

Figure 2: Abundance of lianas (circles) and trees and shrubs (triangles; $\geq 2.5 \mathrm{~cm}$ diameter) in 66 tropical lowland forests elevation ( $\leq 1,000)$ from Africa (8), Asia (4), Central America (9), and South America (45) regressed over mean annual precipitation (data from Phillips and Miller 2002). Neotropical sites are represented by solid symbols and paleotropical sites by open symbols. Liana abundance decreased significantly with increasing precipitation $\left(P=.01, R^{2}=0.10, n=65\right)$, while the increase in tree abundance was marginally significant $\left(P=.097, R^{2}=0.10, n=65\right)$. The wettest site $(\sim 7,500 \mathrm{~mm}$ precipitation), while shown, was excluded for curve fitting to provide a more conservative test. Inclusion of this site did not alter the results for lianas $\left(P=.006, R^{2}=0.11, n=66\right)$; however, the increase in tree abundance was highly significant with this point $\left(P=.008, R^{2}=0.16, n=66\right)$.

India, increasing considerably in abundance with increasing seasonality (Parthasarathy et al. 2004).

In contrast, lianas are relatively sparse in aseasonal wet tropical forests. For example, Gentry's own data demonstrate that lianas $(\geq 2.5 \mathrm{~cm}$ diameter) are significantly less abundant in wet forests $\left(533 \pm 72 \mathrm{ha}^{-1}\right)$ than in dry forests $\left(779 \pm 50 \mathrm{ha}^{-1}\right)$. Liana abundance and estimated biomass were more than $50 \%$ lower in the aseasonally wet forest of La Selva Biological Station in Costa Rica than in the seasonal moist forest of BCI (DeWalt and Chave 2004; Mascaro et al. 2004). DeWalt and Chave (2004) censused the lianas in four Neotropical forests and found that, although the differences were not significant, the three seasonal forests had, on average, more than twice the number of lianas as the one aseasonal forest. Even in relatively liana-dense wet forests, such as Yasuní in Ecuador, liana abundance was considerably lower than in liana-dense seasonally dry forests (see Pérez-Salicrup et al. 2001; Burnham 2002). Consequently, both new and previously published data support the hypothesis that, as a general trend, liana abundance and basal area decrease with increasing rainfall, peaking in dry forests with relatively severe seasonal droughts while remaining in low abundance in wet, less seasonal forests.

\section{A Mechanistic Explanation for the Pantropical Distribution of Liana Abundance}

The unique ecological, anatomical, and physiological adaptations of lianas may explain why they are found in the greatest abundance in tropical forests that regularly experience seasonal droughts. Lianas have extremely deep and efficient root and vascular systems and thus may be able to tap water and nutrients that many trees and shrubs are unable to access during drought conditions. In addition, light, which is typically limiting in tropical forests, is more abundant during the dry season (Wright 1996; Graham et al. 2003). Because lianas can access water, they can capitalize on increased dry season solar radiation with relatively high growth, whereas many competing trees and shrubs cannot. High dry season growth rates would confer a competitive advantage on lianas, which over decades to centuries may result in their high abundance in seasonal forests. In contrast, in aseasonal forests, where water is 
rarely limiting, lianas are suppressed by competition from other plants because lianas do not have a dry season growth advantage, thus explaining their relative paucity. I further develop this theory and present several independent lines of empirical evidence to support it.

\section{The Unique Anatomy and Physiology of Lianas and the Paradox of Liana Distributions}

One of the primary ways in which lianas differ from trees is that lianas have an extremely high canopy to stem ratio, with long and narrow stems and a proportionally large canopy that can completely cover that of its host tree (Putz 1983; Schnitzer and Bongers 2002). The length of a large liana can far exceed that of even the tallest tree, and a large liana can course through dozens of tree canopies over distances of hundreds of meters (e.g., Putz 1984). The relatively long and narrow stem of lianas, however, also poses a considerable challenge for the transport of sufficient amounts of water and nutrients necessary to support the large canopy. To overcome this challenge, lianas have evolved extremely efficient vascular systems. Lianas have the widest and longest xylem vessel elements of any plant growth form and a high sapwood to heartwood ratio, both of which facilitate the efficient water transport (Ewers and Fisher 1989; Gartner et al. 1990; Ewers et al. 1991; Holbrook and Putz 1996; Tyree and Ewers 1996). Because water flow increases to the fourth power with the radius of cylindrical vessel elements, the wide vessels of lianas can transport water more efficiently than other vascular plants (Holbrook et al. 1995). The vascular systems of lianas are further modified with such adaptations as reduced perforation plates, which decrease resistance to water flow and enhance vascular transport efficiency (Carlquist 1991).

These adaptations for efficient vascular transport, however, come at an ecological cost: specifically, a higher risk of embolism, which could force plants to become dormant during seasonal droughts or else render vessels permanently nonconductive (Ewers et al. 1990; Gartner et al. 1990). Additionally, the extremely wide vessel elements housed in a slender stem result in each wide vessel contributing a relatively high proportion to the total conductive vascular area, and thus an embolized vessel may be especially devastating to the functioning of the entire plant. In contrast, shorter and narrower vessel elements are less likely to become embolized, and a single, small embolized vessel has a lower systemic impact (Sperry et al. 1987). For example, lianas and trees growing in extremely dry forests appear to have slightly narrower vessels than those of the same species in more mesic forests, reducing the possibility of embolism (Gartner et al. 1990; Sobrado 1993). Even within a dry forest, plants that retain their leaves throughout the dry season appear to have narrower vessels compared with plants that are drought deciduous (Sobrado 1993; Holbrook et al. 1995). Lianas, however, may be restricted to maintaining some relatively large vessels because of their narrow stems and the necessity to transport water to a large canopy. Paradoxically, lianas peak in abundance in strongly seasonal dry tropical forests, where they are most vulnerable to embolism.

\section{Resolving the Paradox: Lianas Avoid Embolism via Tapping Deep Sources of Soil Moisture}

This apparent paradox may be explained by the ability of lianas to access deep sources of water, even in forests with strong seasonal droughts. By developing exceptionally deep and wide root systems, lianas may ensure a relatively constant supply of water and thus reduce the risk of embolism (Tyree and Ewers 1996; Wright 1996; Andrade et al., forthcoming). For example, Restom and Nepstad (2004) excavated liana seedlings of the species Davilla kunthii (Dilleniaceae) in a secondary forest in eastern Amazonia and found that their root systems were often more than eight times longer than the aboveground stem, with the roots of very small individuals exceeding $10 \mathrm{~m}$ in depth. In addition, liana root systems may be wider in diameter than the stems that they supply. Tyree and Ewers (1996) reported that the diameter of the root system of the liana species Machaerium milleflorum (Fabaceae) was nearly eight times wider than the diameter of its stem. Lianas may be able to develop particularly deep and wide root systems because they invest relatively little energy into structural support compared with trees, and thus lianas can grow to great lengths both aboveground and belowground (Holbrook and Putz 1996).

Having deep root systems may prevent lianas from suffering as much water stress during the dry season as trees. Using deuterium isotopes to determine the depth in the soil at which woody plants accessed water throughout the dry season on BCI in Panama, Andrade et al. (forthcoming) found that lianas consistently tapped water from deeper sources as the dry season progressed, whereas many tree species in this forest did not (Meinzer et al. 1999). Further evidence that lianas have access to sources of water during the dry season is their ability to produce and expand stems, leaves, and flowers during this period (Longino 1986; Putz and Windsor 1987), processes requiring a substantial supply of water. This production and expansion during the dry season may be aided by the ability of lianas to store small amounts of water in unlignified parenchymatous cells in their stems, which become depleted during the day and recharged at night (Ewers et al. 1991; Fisher and Ewers 1991).

Embolism repair via positive root pressure has been 
proposed as an alternative strategy for lianas to remain active during seasonal droughts (e.g., Holbrook and Putz 1996). This strategy, however, does not appear to be used by many tropical lianas. In a study of predawn root pressures of 32 liana species from 13 families on BCI $(n=$ 65), Ewers et al. (1997) reported that none of the 29 dicotyledonous lianas generated root pressures that were sufficient to repair embolized vessels in the canopy of the plants. Twenty-six of these species did not generate positive root pressures at all, and the three species that did, all members of the family Dilleniaceae, generated pressures that were too weak to refill vessels higher than $6.4 \mathrm{~m}$ on their $18+-m$-tall stems. Two other liana species, a climbing fern (Lygodium venustrum) and a climbing bamboo (Rhipidocladum facemiflorum), generated root pressures sufficient to refill embolized vessels in the canopy of the plant. Both of these species, however, are relatively small in stature, and thus only modest positive root pressures were necessary to push water up to their canopies (Tyree and Ewers 1996).

\section{Lianas Remain Photosynthetically Active during Seasonal Droughts}

Another strategy of plants to avoid embolism and water stress during seasonal droughts is to become deciduous or physiologically dormant. Although many broad-leaved plants employ this strategy, most lianas appear to retain leaves and remain active throughout the dry season in many forests. For example, in the seasonal moist forest on $\mathrm{BCI}$, nearly all of the 175 species of liana remain evergreen throughout the year, whereas nearly $30 \%$ of the trees lose their leaves at some point during the dry season (Croat 1978; Putz and Windsor 1987; Condit et al. 2000). Likewise, in a dry forest in the Guanacaste Province in northwest Costa Rica, which has severe and extended seasonal droughts, Opler et al. (1991) reported that many liana species were evergreen throughout the dry season and that production of new leaves began late in the dry season, presumably when water was the most scarce. Kalácska et al. (2005) also found that lianas retained their leaves throughout most of the dry season in a dry forest in the Guanacaste Province, with liana species becoming deciduous only at the very end of the season, far later than most of the trees.

Lianas appear to remain photosynthetically active during seasonal droughts. In the seasonal moist forest of BCI, Zotz and Winter (1996) reported that the tropical liana Uncaria tomentosa maintained the same rate of photosynthesis during the dry and wet seasons. Additional support comes from Castellanos (1991), who found that the stomatal conductance of the only liana measured during the dry season in a Mexican tropical dry forest (Aristolochia sp.) was similar to the wet season stomatal conductance of other liana species, suggesting that liana stomatal conductance remains high throughout the year. During the particularly severe El Niño drought in 1997-1998, Andrade et al. (forthcoming) found that sap flow in six liana species on BCI continued throughout the dry season, indicating that lianas remained active even during severe seasonal droughts despite increasing air saturation deficit. Similar sap flow patterns were also observed in two liana species in a very dry tropical forest in Mexico (Fichtner and Schulze 1990).

\section{Does Effective Water Foraging Translate into Increased Liana Growth Rates during the Dry Season?}

Reduced cloud cover during the dry season increases solar radiation, which can increase leaf production, carbon fixation, and reproduction in those plants that are not water stressed (Wright and van Schaik 1994; Wright 1996; Zotz and Winter 1996; Graham et al. 2003). On BCI, daily photosynthetically active radiation recorded above the canopy increased by nearly $50 \%$ during the dry season compared with the wet season (Wright and van Schaik 1994). In addition, canopy leaf cover declined by $10 \%$ from the wet to dry seasons on BCI and by nearly $20 \%$ in the dry forest of Cocoli (Condit et al. 2000). More light reaching the canopy and fewer canopy leaves to intercept that light will allow more light to reach the forest floor during the dry season. By experiencing less water stress during the dry season and being able to rapidly respond to increases in light (Avalos and Mulkey 1999), lianas should be able to capitalize on the increase in light with superior growth rates compared with trees. Over decades, the advantage of relatively high dry season growth rates may allow lianas to increase in abundance in seasonal forests.

I tested the hypothesis that lianas grow proportionally more rapidly than trees during the dry season compared with the wet season in the shaded understory of an oldgrowth seasonal moist forest on BCI. During a 12-month period in 1998 and 1999, I measured the height growth of 10 liana and 12 tree species (384 individuals total) from 19 genera and 17 families (table 1). All individuals were between 1 and $2.5 \mathrm{~m}$ tall. In April 1998, at the beginning of the wet season, I marked individuals precisely $5 \mathrm{~cm}$ below the tip of the apical meristem with a black permanent marker. I measured the height of all individuals 8 months later at the end of the wet season, in December 1998, and again 4 months after that at the end of the dry season, in April 1999. For all lianas and trees, I converted mean seasonal height growth per species to an annual rate and compared these growth rates using an ANOVA, with the mean height growth rate per species as the unit of replication and growth form, season, and the interaction 
Table 1: Liana and tree species (and family) for which growth rates were measured during the wet and dry seasons on Barro Colorado Island, Panama

\begin{tabular}{ll}
\hline Trees & \multicolumn{1}{c}{ Lianas } \\
\hline Alseis blackiana (Rubiaceae) & Callichlamys latifolia (Bignoniaceae) \\
Capparis frondosa (Capparidaceae) & Coccoloba parimensis (Polygonaceae) \\
Desmopsis panamensis (Annonaceae) & Connarus turczaninowii (Connaraceae) \\
Faramea occidentalis (Rubiaceae) & Doliocarpus olivaceus (Dilleniaceae) \\
Garcinia intermedia (Clusiaceae) & Hiraea reclinata (Malpighiaceae) \\
Hirtella triandra (Chrysobalanaceae) & Paullinia bracteosa (Sapindaceae) \\
Hybanthus prunifolius (Violaceae) & Paullinia fibrigera (Sapindaceae) \\
Mouriri myrtilloides (Melastomataceae) & Paullinia pterocarpa (Sapindaceae) \\
Pouteria reticulata (Sapotaceae) & Paullinia turbacensis (Sapindaceae) \\
Protium panamense (Burseraceae) & Petrea aspera (Verbenaceae) \\
Swartzia simplex (Caesalpinioideae) & \\
Tetragastris panamensis (Burseraceae) & \\
\hline
\end{tabular}

term as the independent variables (SAS Institute 2000). To ensure that the mean liana height growth rates were not biased by the four congeneric Paullinia species, I also analyzed the data using the mean of all of the four congenerics combined rather than treating them as independent replicates $(n=7)$. The results of these two analyses did not differ, so I present the results from the larger data set $(n=10)$.

Both lianas and trees grew significantly more in height during the wet season than during the dry season $(P=$ $.001, F=12.02, \mathrm{df}=1,42)$, demonstrating that both growth forms suffered from water stress during the dry season. The annual growth rate of lianas was significantly greater than that of trees $(P=.009, F=7.59, \mathrm{df}=$ 1,42; fig. 3), and lianas grew nearly two times more than trees during the wet season. In the dry season, however, liana growth rate outpaced that of trees by nearly sevenfold, demonstrating that lianas suffered substantially less water stress than trees. In fact, trees grew very little during the dry season, perhaps because they shut down in order to survive the seasonal drought. These findings support the hypothesis that liana abundance is high in seasonal forests because of their ability to grow more than competing trees during the periods of seasonal drought. In contrast, the decrease in tree abundance and forest productivity with decreasing precipitation may be explained by the inability of trees to grow during the dry season combined with the intense competition with lianas (e.g., Schnitzer and Bongers 2002; Grauel and Putz 2004).

\section{Additional Evidence That Lianas Are Not Water Stressed during the Dry Season}

Wright and van Schaik (1994) suggested that there should be strong selection on plants to produce new leaves during the dry season because new leaves are more photosynthetically efficient than are older leaves, and thus they can take advantage of the increase in dry season radiation. In addition, young leaves, which are attacked preferentially by herbivores, may avoid being eaten during the dry season, when herbivore abundance is low (Coley 1983). However, the ability to expand new leaves, flowers, and stems requires an ample supply of water (Holbrook et al. 1995), and thus selection should favor the production of new leaves during the dry season only for plants that are less susceptible to water stress.

Because lianas can access deep soil moisture, they may provide better support for the model proposed by Wright and van Schaik (1994) than other plant groups. Indeed, Putz and Windsor (1987) examined the phenology of 43 liana species on BCI and reported that nearly all species produced new leaves throughout the dry season. In contrast, less than half of the 26 species of tree they examined produced new leaves during this season (Putz and Windsor 1987). A substantial proportion of liana species also produced flowers during the dry season, whereas very few trees flowered during this period (Putz and Windsor 1987). Longino (1986) reported similar results in a seasonal forest in Costa Rica, where the shoot production of the liana Passiflora pittieri was extremely high during the dry season.

Not only are lianas able to access deep sources of water through extensive root systems, but they also appear to be better competitors for shared soil resources than are trees. For example, in an experimental study disentangling aboveground versus belowground competition of lianas on trees in a disturbed forest, S. A. Schnitzer, M. Kuzee, and F. Bongers (unpublished manuscript) demonstrated that belowground competition, rather than aboveground interaction, was the mechanism by which lianas significantly reduced the aboveground growth of tree saplings. In a seasonal tropical forest in Bolivia, Pérez-Salicrup and Barker (2000) experimentally cut lianas from Senna multijuga trees and found that, although soil moisture did not measurably change, the predawn water potential of these 


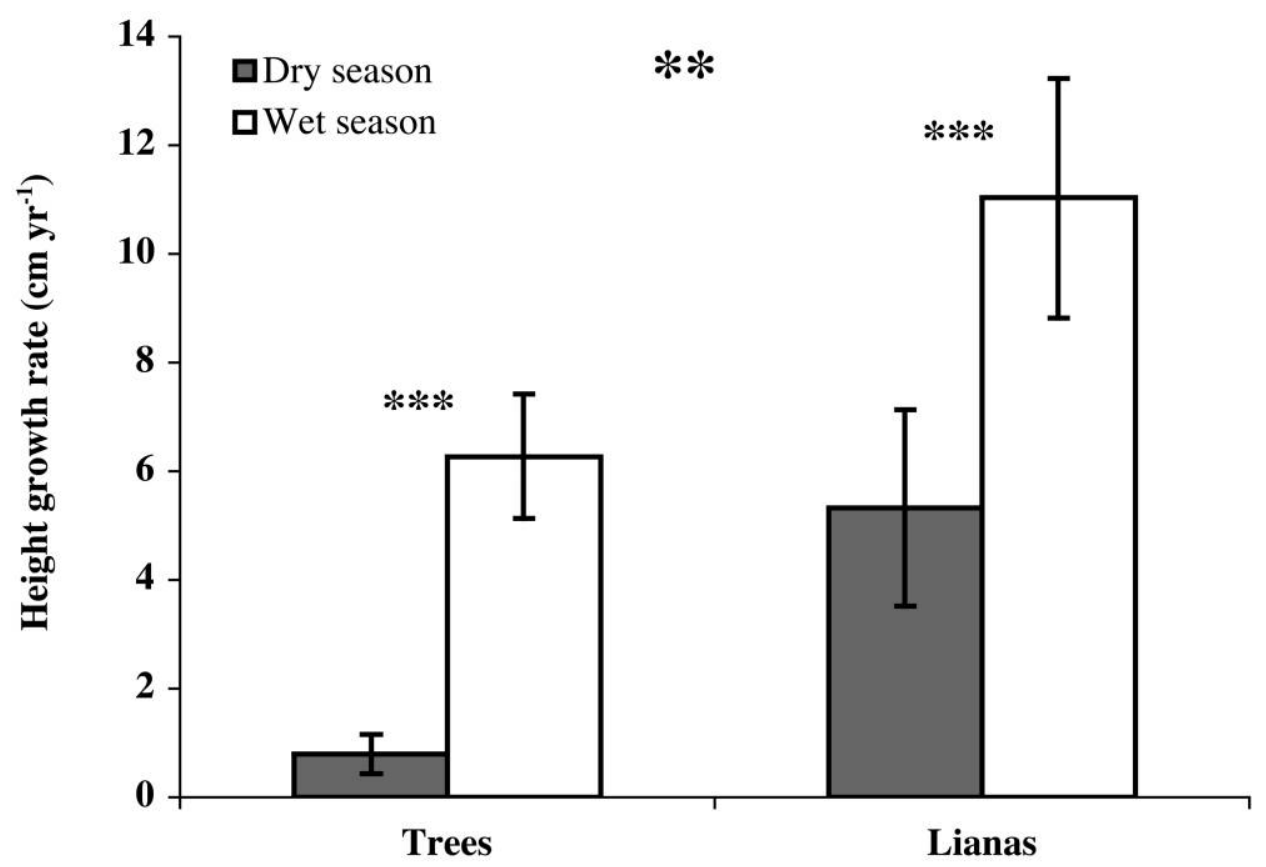

Figure 3: Annual height growth rate (scaled to 12 months) of lianas $(n=10)$ and trees $(n=12)$ during the wet and dry seasons on Barro Colorado Island, Panama. Growth rates for both lianas and trees were significantly higher in the wet season than the dry season $(P=.001, F=12.02$, $\mathrm{df}=1,42)$, and lianas grew significantly more than trees $(P=.009, F=7.59, \mathrm{df}=1,42)$. Liana growth rate was nearly twice as much as trees during the wet season but more than seven times that of trees during the dry season. These differences were the same regardless of whether growth was annualized or examined over the 4-month dry season and 8-month wet season.

trees became significantly less negative within 1 day after cutting the lianas, suggesting strong competition for water between lianas and this particular tree species (but see Barker and Pérez-Salicrup 2000). In a series of controlled competition experiments between sweetgum trees ( Liquidambar styraciflua) and two species of temperate zone lianas, competition from lianas for nitrogen drastically reduced tree growth (Dillenburg et al. 1993a, 1993b, 1995). Indirect evidence also suggests that belowground competition plays a potentially large role in liana-tree competition. In a study in the Darien region of Panama, Grauel and Putz (2004) compared the growth of trees in plots in which all of the lianas were removed and plots in which lianas were left uncut, and they found that trees grew significantly more in the absence of lianas. On a per tree basis, however, this relationship was largely independent of the number of lianas in the canopy of a given tree, suggesting that lianas were competing more for a shared soil resource than for light. Collectively, these studies support the hypothesis that lianas are adept at acquiring belowground resources and efficiently transporting them to their canopy.

\section{Does Liana Abundance Decrease in Extremely Dry Tropical Forests?}

In theory, liana abundance should begin to decrease in exceedingly dry forests, where even lianas themselves cannot tolerate the high water stress, air saturation deficit, and threat of drought-induced embolism. The point along the rainfall and seasonality gradient where lianas begin to decrease in abundance, however, has not yet been determined. The mean abundance of lianas of the two driest lowland forests from the Gentry data set (mean annual rainfall: 500 and $800 \mathrm{~mm}$ ) was essentially the same as in the mean of the rest of the dry forests, which ranged in mean annual rainfall from 1,000 to $1,920 \mathrm{~mm}(81.5 \pm$ 24.5 vs. $78.2 \pm 6.9$ lianas $0.1 \mathrm{ha}^{-1}$, respectively; Phillips and Miller 2002). Mean liana abundance was also similar in the extremely dry forest at Chamela Biological Station in Jalisco, Mexico (77.7 \pm 31.9 individuals $0.1 \mathrm{ha}^{-1}$; Phillips and Miller 2002), where mean annual rainfall is only $748 \mathrm{~mm}$ per year, with merely $\sim 150 \mathrm{~mm}$ of rain falling during the 8-month dry season (Lott et al. 1987). Indeed, even at Chamela, some select lianas remained evergreen during the dry season (Fichtner and Schulze 1990; Gartner 
et al. 1990). These evergreen species, however, probably resided in the relatively moist arroyos, where vines were three times more abundant than on the dry hillsides (Lott et al. 1987; Phillips and Miller 2002).

\section{Explaining the Local Distribution of Lianas in Tropical Forests}

The same mechanism that enables lianas to proliferate in seasonally dry tropical forests may also explain their abundance at the local scale within forests. Although several hypotheses have been proposed to explain the clumped distribution of lianas within a given forest (reviewed in Schnitzer and Bongers 2002), the hypothesis that disturbance promotes liana proliferation and maintains liana abundance has received the most convincing empirical support (e.g., Putz 1984; Smith 1984; Teramura et al. 1991; Schnitzer and Carson 2000, 2001; Schnitzer et al. 2000, 2004). For example, at the relatively small spatial scale of a treefall gap, Schnitzer and Carson (2001) demonstrated that lianas in a tropical forest in Panama were more than twice as abundant in 5- and 10-year-old naturally occurring treefall gaps when compared with the same-sized nongap sites, whereas tree abundance did not differ between the gap and nongap sites. Large-scale forest disturbances from both natural and anthropogenic forces also result in considerable increases in liana abundance. For example, in a chronosequence of tropical forests in central Panama, liana abundance was significantly greater in regenerating young secondary forests (20-40 years old) than in older forests (70, 100, and $>500$ years old; DeWalt et al. 2000). Other large-scale disturbances, such as those from hurricanes, can also result in substantial increases in liana abundance (Horvitz et al. 1998; but see Rice et al. 2004). Likewise, forest fragmentation appears to increase liana abundance. In central Amazonia, liana abundance was significantly higher within $100 \mathrm{~m}$ of forest edges than in forest interiors (Laurance et al. 2001).

The attributes that enable lianas to compete well in seasonally dry tropical forests may also allow them to proliferate following disturbance. The relatively high temperatures and evaporative gradients as well as the low humidity in treefall gaps, young secondary forests, and forest edges are often too severe for the survival of many plants, especially those adapted to the conditions of the shaded understory (Mulkey and Wright 1996). These relatively harsh conditions, however, may be similar to those found in tropical dry forests, and the ability of lianas to tolerate dry conditions may allow them to capitalize on the high light availability following disturbance. Furthermore, when light is no longer the most limiting factor, as is commonly the case following disturbance, belowground competition may become more intense (e.g., Putz and Canham 1992), which would favor the deep and efficient root systems of lianas over more shallow-rooted plants, such as many tree species (Dillenburg et al. 1993a, 1995; Pérez-Salicrup and Barker 2000). Consequently, lianas may be particularly abundant in disturbed forests and in disturbed areas within forests, because they are able to capitalize on the high light availability while suffering relatively low water stress.

Although disturbance may explain the local distribution of lianas within a given forest, disturbance rate as a predictor of liana abundance among forests may be relatively weak compared with annual precipitation and seasonality. Tropical wet forests, where liana abundance is more consistently low (fig. 2), have the highest frequency of treefall gaps, presumably because of the combination of high winds and waterlogged soils (reviewed by Denslow and Hartshorn 1994). Liana abundance is also low in the evergreen forests in Puerto Rico, which experience high disturbance from hurricanes (Rice et al. 2004). The loss of a dry season advantage (because soil moisture availability may always remain fairly high), combined with the relatively low light conditions in the understory and the burden of year-round competition from other plants, may suppress liana abundance, regardless of the relatively high rates of disturbance. In contrast, only in seasonal forests, where lianas have the potential to reach relatively high abundance because of their ability to capitalize on light during the dry season, will local factors, such as disturbance, contribute to local liana abundance. The contribution of local factors may be indicated by the relatively high variability in liana abundance among seasonally dry forests (figs. 1, 2).

Edaphic factors, such as soil nutrient and moisture availability, may, to some extent, also explain local and pantropical liana distribution, particularly in seasonally dry forests. Soil nutrient availability tends to vary negatively with mean annual precipitation in tropical forests (Clinebell et al. 1995), and thus low liana abundance in wet forests could be attributed, in part, to low levels of soil nutrients (Putz and Chai 1987; Laurance et al. 2001; DeWalt and Chave 2004). Empirical support for the hypothesis that nutrient levels control liana abundance and distribution within and among forests, however, is limited (reviewed by Schnitzer and Bongers 2002). Although lianas tend to increase in abundance slightly with increasing nutrient levels, this relationship is highly variable and relatively unpredictable (Gentry 1991; Schnitzer and Bongers 2002; DeWalt and Chave 2004). The variance in soil moisture availability with different soil types may provide a better explanation for local liana abundance, with lianas competing best in soils that contain just enough moisture to enable them to grow but cause substantial water stress in other growth forms. 


\section{Explaining the Latitudinal Distribution of Lianas}

The mechanism to explain pantropical patterns of liana abundance presented here also provides a framework with which to explain the distribution of lianas over a latitudinal gradient. Liana abundance is highly variable within the tropics but decreases sharply north of the Tropic of Cancer (fig. 4). The explanation for this precipitous decrease in liana abundance at the boundary of the tropical and temperate zones is that the same general adaptations that allow lianas to efficiently transport water to support a large canopy and thus thrive in tropical forests become maladaptive to their survival in temperate climates (Sperry et al. 1987; Ewers et al. 1991). Specifically, the large vessel elements and relatively thin stems that lack insulation make lianas particularly vulnerable to prolonged freezing conditions. Tropical lianas exposed to freezing temperatures could suffer freezing-induced embolism or even the rupturing of vessel elements, which in either case would render the vascular system inoperable and ultimately kill the plant (Sperry et al. 1987; Ewers et al. 1991, 1997). This explanation is consistent with the pattern shown in figure 4, where the threshold at which liana abundance plummets is close to the latitude where freezing temperatures occur.

The ecological and physiological adaptations of the liana species that persist in the temperate zone support the hypothesis that lianas are limited in range by their vulner- ability to cold winter temperatures. For example, some members of the mostly temperate liana family Vitaceae (the grape family) have extremely large vessel elements but have adapted to cold winter temperatures by completely draining their vessels prior to the onset of winter, thus protecting them from catastrophic freezing and the destruction of their vessel elements (Sperry et al. 1987). In the spring, these species generate extremely high positive root pressures, allowing them to fill their vessels completely before they produce leaves (Sperry et al. 1987; Ewers et al. 1991). In contrast, Oriental bittersweet (Celastrus orbiculatus), which is currently invading forests of North America, exhibits no positive root pressure but instead may survive freezing winters by producing new functional xylem in the spring (Tibbets and Ewers 2000). Other liana species deal with cold winter temperatures by changing their physiognomy. Poison ivy (Toxicodendron radicans), which commonly grows as a large climbing liana in much of the eastern and midwestern portions of the United States, is present only as a low-growing, trailing vine in the extremely cold climate of the far northern United States and in Canada (Voss 1985). The low-growing and climbing forms of poison ivy may be different but closely related species (Gillis 1971), and, if so, it is possible that the adaptation to the cold climate was the mechanism for this divergence. Other temperate liana species may have

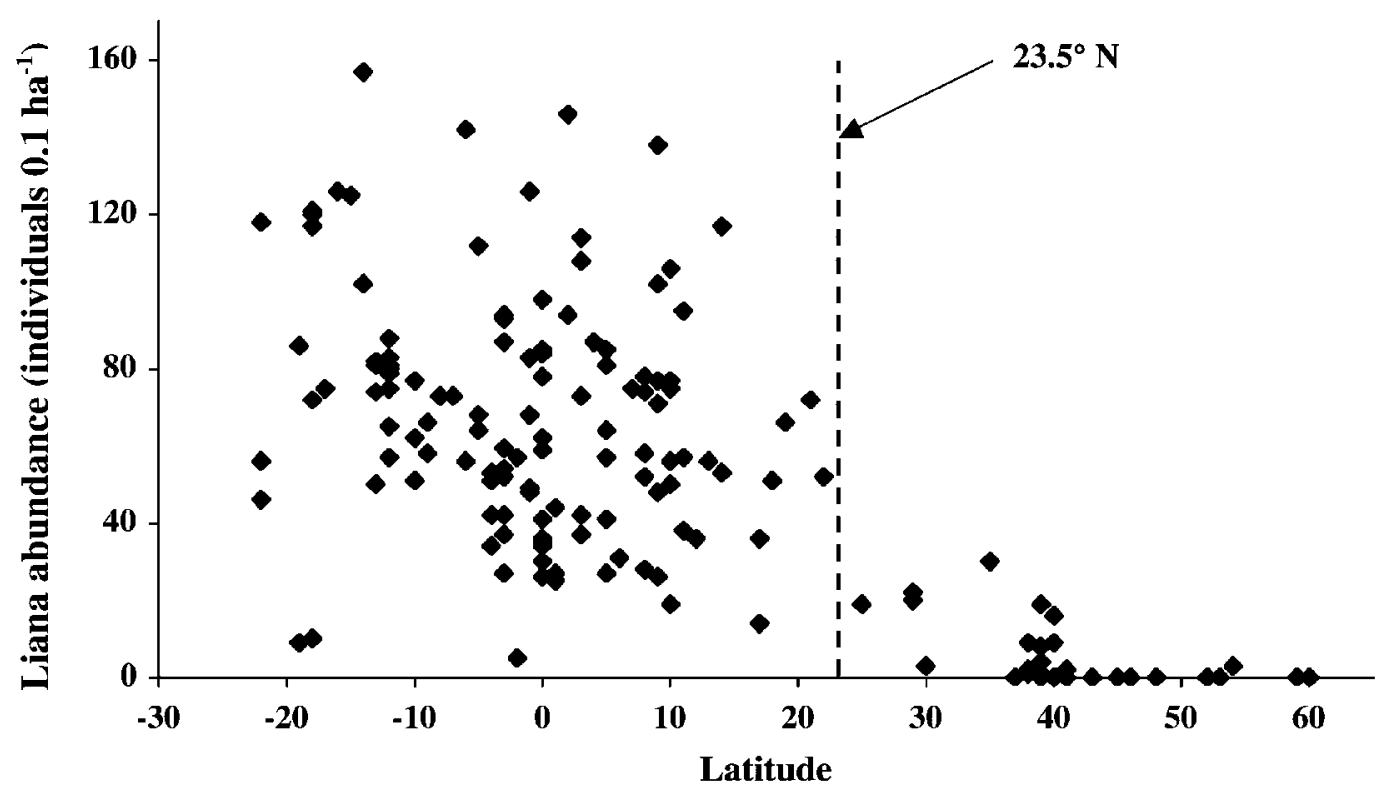

Figure 4: Latitudinal gradient in liana abundance from tropical lowland forests $\left(23.5^{\circ} \mathrm{S}-23.5^{\circ} \mathrm{N}\right)$ to Northern Hemisphere lowland forests. Each forest had a mean annual rainfall $\geq 500 \mathrm{~mm}$ and was $\leq 1,000 \mathrm{~m}$ in elevation (data from Phillips and Miller 2002). The dashed line represents the approximate location of the Tropic of Cancer $\left(23.5^{\circ} \mathrm{N}\right)$. There was a significant linear decrease in liana abundance with increasing latitude $(P<$ $\left..0001, R^{2}=0.46, n=155\right)$, but the decrease in liana abundance with latitude is better represented by a step function, with liana abundance varying considerably in the tropics but suppressed at relatively low levels north of the Tropic of Cancer. 
smaller than average vessel elements, which in theory could allow them to survive in moderately cold temperatures, such as the conditions found at low temperate latitudes or higher altitudes in the tropics.

Lianas may suffer an additional disadvantage in temperate forests because they may lose their leaves earlier than tree species in order to prevent vessel damage from occasional early frosts. For example, leaves of many liana species, such as Vitis spp., Parthenocissus spp., and T. radicans, begin to senesce and fall much earlier than those of their host trees, resulting in a growing season that is shorter than that for many trees (Stiles 1982). Although Stiles (1982) argued that early senescence by the lianas Parthenocissus spp. and T. radicans is an adaptation for seed dispersal (foliar fruit flag hypothesis), this early senescence may also be determined by the vulnerability of lianas to early frosts and their need to prepare for winter (e.g.) drain their vessel elements in the case of the Vitaceae). Collectively, these examples support the hypothesis that the striking decrease in liana abundance north of the tropics is driven by trade-offs of fast growth, slender stems, and a highly efficient vascular system, all of which are beneficial in warm climates but detrimental in cold ones.

\section{Implications for Forest Dynamics}

Understanding the mechanisms responsible for patterns of plant species abundance and distribution may lead to insights into the regeneration and dynamics of plant communities. For instance, the theory presented here allows for clear and testable predictions of how liana distributions may change with changing climatic conditions. If seasonal droughts in the Neotropics, such as those associated with El Niño or deforestation, are increasing in frequency or duration, as some have argued (Trenberth and Hoar 1997; Timmerman et al. 1999), then the theory presented here would predict that liana abundance and biomass will also increase in this region.

Increases in liana abundance and biomass may already be occurring throughout the Neotropics. Phillips et al. (2002) reported that the proliferation of large lianas ( $>10$ $\mathrm{cm}$ diameter) throughout nonfragmented Amazonian forests has increased as much as $4.6 \%$ per year over the last 2 decades, nearly doubling in abundance over this 20 -year period. Wright et al. (2004) supported these findings, reporting that liana leaf litter in the old-growth forest on BCI increased by nearly $40 \%$ over the 17 -year period from 1986 to 2002.

On the basis of the theory presented here, the increases in liana abundance and biomass could be due to the decrease in precipitation or the increase in the rate of disturbance. The forest on BCI, where Wright et al. (2004) found such profound increases in liana abundance, has experienced a steady decrease in annual precipitation of nearly 20\% during the 60-year period from 1930 until 1990 (data averaged over a 10-year period; Meteorology and Hydrology Branch, Panama Canal Authority, Republic of Panama). Even though rainfall has subsequently increased nearly back to 1930 levels during the 1990s, the 60-year decrease may have favored the growth of lianas over that of trees. Likewise, forests throughout the Neotropics may also suffer from increased water stress because of an increase in the frequency of El Niño-related droughts (Dunbar 2000), which can increase the abundance of lianas by extending the duration and severity of the dry season as well as by increasing treefall gap formation in subsequent years (Condit et al. 1995). Forest productivity also appears to be increasing in the Amazon (Phillips and Gentry 1994; Phillips 1998; Laurance et al. 2004), resulting in higher rates of tree mortality and disturbance, which would provide the habitat favorable for liana proliferation. An alternative but not mutually exclusive explanation for the increase in liana abundance is the increase in atmospheric carbon, which may elevate liana growth rates and thus elevate their competitive ability (Granados and Körner 2002; Hättenschwiler and Körner 2003). This latter explanation, however, remains to be tested under natural conditions.

Over the last 45 years, some liana species (e.g., Parthenocissus sp.) have increased substantially in abundance in temperate forests (S. A. Schnitzer, unpublished data). One potential explanation for this increase may be attributed to increased forest disturbance and fragmentation in temperate forests in North America over the last half century, mainly because of deforestation and road construction (Ritters and Wickham 2003). The steady increase in minimum winter temperatures over the last several decades (e.g., Walther et al. 2002) may also contribute to the increase in liana abundance as more lianas survive the winter. Warmer winter temperatures may also allow lianas to expand poleward into forests that were previously liana free (sensu Root et al. 2003).

The explanations for the increase in liana abundance in temperate regions may be extended to predict the increase in liana abundance with increasing altitude in the tropics. Currently, lianas are scarce in tropical montane forests (Gentry 1991), possibly because the abundant clouds and year-round precipitation work against the competitive strengths of lianas. The trend of increasing temperature and lower cloud cover and precipitation in high-altitude tropical forests (Still et al. 1999), however, may permit lowland lianas to invade these forests.

\section{Conclusions}

Liana abundance increases with decreasing precipitation and increasing seasonality, peaking in tropical dry forests. 
I propose that the mechanism responsible for this pattern is the extensive root and efficient vascular systems of lianas, which allow them to suffer less from water stress and thus grow substantially more than trees during the dry season. This capacity of lianas to grow while competing trees are mostly dormant confers a competitive advantage that, over time, may explain the high abundance of lianas in seasonal forests throughout the tropics. In contrast, the consistent paucity of lianas in aseasonal wet forests may be due to the lack of this dry season competitive advantage. The ability of lianas to increase in abundance following disturbance within a given forest may be due to a similar mechanism. Specifically, lianas may suffer less water stress in the relatively harsh conditions following disturbance and thus are better able to capitalize on the abundant light than many other growth forms.

This proposed mechanism may be extended to explain the latitudinal distribution of lianas, where liana abundance decreases dramatically outside of the tropics. The slim stems and efficient vascular systems that confer an advantage to lianas in seasonal tropical forests become an impediment to survival in cold climates, and only a small subset of lianas has the appropriate adaptations that permit survival outside of the tropics. The mechanistic explanation for the global patterns of liana abundance presented here allow for clear and testable hypotheses for the potential change in liana abundance and distribution with increasing global change, including increases in disturbance, temperature, and the severity and duration of seasonal droughts in forests worldwide.

\section{Acknowledgments}

I am grateful to J. L. Andrade, N. Brokaw, S. DeWalt, A. Ercoli, P. Fine, J. Hille Ris Lambers, J. Karron, A. Malizia, S. Paton, F. Putz, L. Santiago, P. Stephens, J. Wright, and an anonymous reviewer for helpful comments and discussions on this manuscript. S. Fernandez and B. Kurzel assisted with data collection in Panama. Rainfall data were generously provided by the Meteorology and Hydrology Branch, Panama Canal Authority, Republic of Panama. This work was made possible by support from the following organizations: Andrew Mellon Foundation Research Exploration Award in Tropical Biology, Garden Club of Allegheny County, Phipps Botanical Garden and Conservancy, Sigma Xi, Smithsonian Tropical Research Institute, and National Science Foundation grants DEB 02-12054 and DEB 96-15184.

\section{Literature Cited}

Andrade, J. L., R. Meinzer, G. Goldstein, and S. A. Schnitzer. Forthcoming. Water uptake and transport in lianas of a seasonally dry tropical forest. Trees: Structure and Function.
Avalos, G., and S. S. Mulkey. 1999. Photosynthetic acclimation of the liana Stigmaphyllon lindenianum to light changes in a tropical dry forest canopy. Oecologia (Berlin) 120:475-484.

Balée, W., and D. G. Campbell. 1990. Evidence for the successional status of liana forest (Xingu river basin, Amazonia Brazil). Biotropica 22:36-47.

Barker, M. G., and D. R. Pérez-Salicrup. 2000. Comparative water relations of mature mahogany (Swietenia macrophylla) trees with and without lianas in a subhumid seasonally dry forest in Bolivia. Tree Physiology 20:1167-1174.

Burnham, R. J. 2002. Dominance, diversity and distribution of lianas in Yansuni, Ecuador: who is on top? Journal of Tropical Ecology 18:845-864.

Carlquist, S. 1991. Anatomy of vine and liana stems: a review and synthesis. Pages 53-72 in F. E. Putz and H. A. Mooney, eds. The biology of vines. Cambridge University Press, Cambridge.

Castellanos, A. E. 1991. Photosynthesis and gas exchange of vines. Pages 181-204 in F. E. Putz and H. A. Mooney, eds. The biology of vines. Cambridge University Press, Cambridge.

Clinebell, R., O. L. Phillips, A. H. Gentry, N. Stark, and H. Zuuring. 1995. Prediction of Neotropical tree and liana species richness from soil and climatic data. Biodiversity and Conservation 4:56-90.

Coley, P. D. 1983. Intraspecific variation in herbivory on two tropical forest tree species. Ecology 64:426-433.

Condit, R., S. P. Hubbell, and R. B. Foster. 1995. Mortality rates of 205 Neotropical tree and shrub species and the impact of a severe drought. Ecological Monographs 65:419-439.

Condit, R., K. Watts, S. A. Bohlman, R. Pérez, R. B. Foster, and S. P. Hubbell. 2000. Quantifying the deciduousness of tropical canopies under varying climates. Journal of Vegetation Science 11: 649-658.

Condit, R., S. Aguilar, A. Hernández, R. Pérez, S. Lao, G. Angehr, S. P. Hubbell, and R. B. Foster. 2004. Tropical forest dynamics across a rainfall gradient and the impact of an El Niño dry season. Journal of Tropical Ecology 20:51-72.

Croat, T. B. 1978. Flora of Barro Colorado Island. Stanford University Press, Stanford, CA.

Dattaraja, H. S., and R. Sukumar. 2004. Tropical dry forest diversity of Mudumalai, Southern India. Inside CTFS 2004, pp. 8-9.

Denslow, J. S., and G. S. Hartshorn. 1994. Treefall gap environments and forest dynamic processes. Pages 120-127 in L. A. McDade, K. S. Bawa, H. A. Hespenheide, and G. S. Hartshorn, eds. La Selva ecology and natural history of a Neotropical rain forest. University of Chicago Press, Chicago.

DeWalt, S. J., and J. Chave. 2004. Structure and biomass of four lowland Neotropical forests. Biotropica 36:7-19.

DeWalt, S. J., S. A. Schnitzer, and J. S. Denslow. 2000. Density and diversity of lianas along a chronosequence in a central Panamanian lowland forest. Journal of Tropical Ecology 16:1-9.

Dillenburg, L. R., D. F. Whigham, A. H. Teramura, and I. N. Forseth. 1993a. Effects of below- and aboveground competition from the vines Lonicera japonica and Parthenocissus quinquefolia on the growth of the tree host Liquidambar styraciflua. Oecologia (Berlin) 93:48-54.

- 1993b. Effects of vine competition on availability of light, water, and nitrogen to a tree host (Liquidambar styraciflua). American Journal of Botany 80:244-252.

Dillenburg, L. R., A. H. Teramura, I. N. Forseth, and D. F. Whigham. 1995. Photosynthetic and biomass allocation responses of Liquid- 
ambar styraciflua (Hamamelidaceae) to vine competition. American Journal of Botany 82:454-461.

Dirzo, R. 2001. Tropical forests. Pages 251-276 in F. S. Chapin, O. E. Sala, and E. Hubert-Shannwald, eds. Global biodiversity in a changing environment. Springer, New York.

Dunbar, R. B. 2000. El Niño: clues from corals. Nature 407:956-959.

Ewers, F. W., and J. B. Fisher. 1989. Variation in vessel length and diameter in stems of six tropical and subtropical lianas. American Journal of Botany 76:1452-1459.

Ewers, F. W., J. B. Fisher, and S. T. Chiu. 1990. A survey of vessel dimensions in stems of tropical lianas and other growth forms. Oecologia (Berlin) 84:544-552.

Ewers, F. W., J. B. Fisher, and K. Fichtner. 1991. Water flux and xylem structure in vines. Pages 127-160 in F. E. Putz and H. A. Mooney, eds. The biology of vines. Cambridge University Press, Cambridge.

Ewers, F. W., H. Cochard, and M. T. Tyree. 1997. A survey of root pressures in vines of a tropical lowland forest. Oecologia (Berlin) 110:191-196.

Fichtner, K., and E. D. Schulze. 1990. Xylem water flow in tropical vines as measured by a steady state heating method. Oecologia (Berlin) 82:350-361.

Fisher, J. B., and F. W. Ewers. 1991. Structural responses to stem injury in vines. Pages $99-124$ in F. E. Putz and H. A. Mooney, eds. The biology of vines. Cambridge University Press, Cambridge.

Gartner, B. L., S. H. Bullock, H. A. Mooney, V. B. Brown, and J. L. Whitlock. 1990. Water transport properties of vine and tree stems in a tropical deciduous forest. American Journal of Botany 77: $742-749$.

Gentry, A. H. 1982. Patterns of Neotropical plant species diversity. Pages 1-84 in M. K. Hecht, B. Wallace, and G. T. Prance, eds. Evolutionary biology. Vol. 15. Plenum, New York.

. 1991. The distribution and evolution of climbing plants. Pages 3-49 in F. E. Putz and H. A. Mooney, eds. The biology of vines. Cambridge University Press, Cambridge.

. 1995. Diversity and floristic composition of Neotropical dry forests. Pages 146-194 in S. H. Bullock, H. A. Mooney, and E. Medina, eds. Seasonally dry tropical forests. Cambridge University Press, Cambridge.

Gillis, W. T. 1971. The systematics and ecology of poison ivy and the poison oaks (Toxicodendron, Ancardiaceae). Rhodora 73:72159.

Graham, E. A., S. S. Mulkey, K. Kitajima, N. G. Phillips, and S. J. Wright. 2003. Cloud cover limits net $\mathrm{CO}_{2}$ uptake and growth of a rainforest tree during tropical rainy seasons. Proceedings of the National Academy of Sciences of the USA 100:572-576.

Granados, J., and C. Körner. 2002. In deep shade, elevated $\mathrm{CO}_{2}$ increases the vigour of tropical climbing plants. Global Change Biology 8:1109-1117.

Grauel, W. T., and F. E. Putz. 2004. Effects on lianas on growth and regeneration of Prioria copaifera in Darién, Panama. Forest Ecology and Management 190:99-108.

Hättenschwiler, S., and C. Körner. 2003. Does elevated $\mathrm{CO}_{2}$ facilitate naturalization of the non-indigenous Prunus laurocerasus in Swiss temperate forests? Functional Ecology 17:778-785.

Holbrook, N. M., and F. E. Putz. 1996. Physiology of tropical vines and hemiepiphytes: plants that climb up and plants that climb down. Pages 363-394 in S. S. Mulkey, R. L. Chazdon, and A. P. Smith, eds. Tropical forest plant ecophysiology. Chapman \& Hall, New York.

Holbrook, N. M., J. L. Whitbeck, and H. A. Mooney. 1995. Drought responses of Neotropical dry forest trees. Pages 243-276 in S. H. Bullock, H. A. Mooney, and E. Medina, eds. Seasonally dry tropical forests. Cambridge University Press, Cambridge.

Holdridge, L. 1967. Life zone ecology. Tropical Science Center, San José, Costa Rica.

Horvitz, C., J. B. Pascarella, S. McMann, A. Freedman, and R. H. Hofstetter. 1998. Regeneration guilds of invasive non-indigenous plants in hurricane-affected subtropical hardwood forests. Ecological Applications 8:947-974.

Kalácska, M., J. C. Calvo-Alvarado, and G. A. Sánchez-Azofeifa. 2005. Calibration and assessment of seasonal changes in leaf area index of a tropical dry forest in different stages of succession. Tree Physiology 25:733-744

Laurance, W. F., D. Pérez-Salicrup, P. Delamonica, P. M. Fearnside, S. Agra, A. Jerozolinski, L. Pohl, and T. E. Lovejoy. 2001. Rain forest fragmentation and the structure of Amazonian liana communities. Ecology 82:105-116.

Laurance, W. F., A. A. Oliveira, S. G. Laurance, R. Condit, H. E. M. Nascimento, A. C. Sánchez-Thorin, T. E. Lovejoy, et al. 2004. Pervasive alteration of tree communities in undisturbed Amazonian forests. Nature 428:171-175.

Leigh, E. G. 1999. Tropical forest ecology. Oxford University Press, New York.

Longino, J. T. 1986. A negative correlation between growth and rainfall in a tropical liana. Biotropica 18:195-200.

Lott, E. J., S. H. Bullock, and J. A. Solis-Magallanes. 1987. Floristic diversity and structure of upland and arroyo forests of coastal Jalisco. Biotropica 19:228-235.

Mascaro, J., S. A. Schnitzer, and W. P. Carson. 2004. Liana diversity, abundance and mortality in a tropical wet forest in Costa Rica. Forest Ecology and Management 190:3-14.

Meinzer, F. C., J. L. Andrade, G. Goldstein, N. M. Holbrook, J. Cavelier, and S. J. Wright. 1999. Partitioning of soil water among canopy trees in a seasonal dry tropical forest. Oecologia (Berlin) 121:293-301.

Mulkey, S., and S. J. Wright. 1996. Influence of seasonal drought on the carbon balance of tropical forests. Pages $187-216$ in S. S. Mulkey, R. L. Chazdon, and A. P. Smith, eds. Tropical forest plant ecophysiology. Chapman \& Hall, New York.

Opler, P. A., H. G. Baker, and G. W. Frankie. 1991. Seasonality of climbers: a review and example from Costa Rican dry forest. Pages 377-391 in F. E. Putz and H. A. Mooney, eds. The biology of vines. Cambridge University Press, Cambridge.

Parthasarathy, N., S. Muthuramkumar, and M. Sridhar Reddy. 2004. Patterns of liana diversity in tropical evergreen forests of peninsular India. Forest Ecology and Management 190:15-31.

Pérez-Salicrup, D. R. 2001. Effect of liana cutting on tree regeneration in a liana forest in Amazonian Bolivia. Ecology 82:389-396.

Pérez-Salicrup, D. R., and M. G. Barker. 2000. Effect of liana cutting on water potential and growth of Senna multijuga (Caesalpiniodae) trees in a Bolivian tropical forest. Oecologia (Berlin) 124:369-475.

Pérez-Salicrup, D. R., V. L. Sork, and F. E. Putz. 2001. Lianas and trees in a liana forest of Amazonian Bolivia. Biotropica 33:34-47.

Pérez-Salicrup, D. R., S. A. Schnitzer, and F. E. Putz, eds. 2004. The community ecology and management of lianas. Forest Ecology and Management 190:1-118.

Phillips, O. L. 1998. Increasing tree turnover in tropical forests as measured in permanent plots. Pages 221-246 in F. Dallmeier and J. A. Comiskey, eds. Forest biodiversity research, monitoring and 
modeling. Man and the biosphere series. Vol. 20. Parthenon, New York.

Phillips, O. L., and A. H. Gentry. 1994. Increasing turnover through time in tropical forests. Science 263:954-957.

Phillips, O. L., and J. S. Miller. 2002. Global patterns of plant diversity: Alwyn H. Gentry's forest transect data set. Missouri Botanical Garden, St. Louis.

Phillips, O. L., R. V. Martinez, L. Arroyo, T. R. Baker, T. Killeen, S. L. Lewis, Y. Malhi, et al. 2002. Increasing dominance of large lianas in Amazonian forests. Nature 418:770-774.

Putz, F. E. 1983. Liana biomass and leaf area of a tierra firme forest in the Rio Negro basin, Venezuela. Biotropica 15:185-189.

- 1984. The natural history of lianas on Barro Colorado Island, Panama. Ecology 65:1713-1724.

Putz, F. E., and C. D. Canham. 1992. Mechanisms of arrested succession in shrublands: root and shoot competition between shrubs and tree seedlings. Forest Ecology and Management 49:267-275.

Putz, F. E., and P. Chai. 1987. Ecological studies of lianas in Lambir National Park, Sarawak, Malaysia. Journal of Ecology 75:523-531.

Putz, F. E., and H. A. Mooney, eds. 1991. The biology of vines. Cambridge University Press, Cambridge.

Putz, F. E., and D. M. Windsor. 1987. Liana phenology on Barro Colorado Island, Panama. Biotropica 19:334-341.

Restom, T. G., and D. C. Nepstad. 2004. Seedling growth dynamics of a deeply-rooting liana in a secondary forest in eastern Amazonia. Forest Ecology and Management 190:109-118.

Rice, K., N. Brokaw, and J. Thompson. 2004. Liana abundance in a Puerto Rican forest. Forest Ecology and Management 190:33-41.

Ritters, K. H., and J. D. Wickham. 2003. How far to the nearest road? Frontiers in Ecology and the Environment 1:125-129.

Root, T. L., J. T. Price, K. R. Hall, S. H. Schneider, C. Rosenzweig, and J. A. Pounds. 2003. Fingerprints of global warming on wild animals and plants. Nature 421:57-60.

SAS Institute. 2000. JMP statistics and graphics guide. Version 4. SAS Institute, Cary, NC.

Schnitzer, S. A., and F. Bongers. 2002. The ecology of lianas and their role in forests. Trends in Ecology \& Evolution 17:223-230.

Schnitzer, S. A., and W. P. Carson. 2000. Have we missed the forest because of the trees? Trends in Ecology \& Evolution 15:375-376.

- 2001. Treefall gaps and the maintenance of species diversity in a tropical forest. Ecology 82:913-919.

Schnitzer, S. A., J. W. Dalling, and W. P. Carson. 2000. The impact of lianas on tree regeneration in tropical forest canopy gaps: evidence for an alternative pathway of gap-phase regeneration. Journal of Ecology 88:655-666.

Schnitzer, S. A., M. P. E. Parren, and F. Bongers. 2004. Recruitment of lianas into logging gaps and the effects of pre-harvesting climber cutting. Forest Ecology and Management 190:87-98.

Smith, H. C. 1984. Forest management guidelines for controlling wild grapevines. USDA Forest Service Northeastern Forest Experiment Station, Research Paper NE-548.

Sobrado, M. A. 1993. Trade-off between water transport efficiency and leaf life-span in a tropical dry forest. Oecologia (Berlin) 96: 19-23.

Sperry, J. S., N. M. Holbrook, M. H. Zimmerman, and M. T. Tyree. 1987. Spring filling of xylem vessels in wild grapevine. Plant Physiology 83:414-417.

Stevens, G. 1987. Lianas as structural parasites: the Bursera simarouba example. Ecology 68:77-81.

Stiles, E. W. 1982. Fruit flags: two hypotheses. American Naturalist 120:500-509.

Still, C. J., P. N. Foster, and S. H. Schneider. 1999. Simulating the effects of climate change on tropical montane cloud forests. Nature 398:608-610.

Teramura, A. H., W. G. Gold, and I. N. Forseth. 1991. Physiological ecology of mesic, temperate woody vines. Pages $245-286$ in F. E. Putz and H. A. Mooney, eds. The biology of vines. Cambridge University Press, Cambridge.

Tibbets, T. J., and F. W. Ewers. 2000. Root pressure and specific conductivity in temperate lianas: exotic Celastrus orbiculatus (Celastraceae) vs. native Vitis riparia (Vitaceae). American Journal of Botany 87:1272-1278.

Timmerman, A., J. Oberhuber, A. Bacher, M. Esch, M. Latif, and E. Roeckner. 1999. Increased El Niño frequency in a climate model forced by future greenhouse warming. Nature 398:694-697.

Trenberth, K. E., and T. J. Hoar. 1997. El Niño and climate change. Geophysical Research Letters 24:3057-3060.

Tyree, M., and F. W. Ewers. 1996. Hydraulic architecture of woody tropical plants. Pages 217-243 in S. S. Mulkey, R. L. Chazdon, and A. P. Smith, eds. Tropical forest plant ecophysiology. Chapman \& Hall, New York.

Voss, E. G. 1985. Michigan flora. II. Dicots. Cranbrook Institute of Science, Ann Arbor, MI.

Walther, G., E. Post, P. Convey, A. Menzel, C. Parmesan, T. Beebee, J. Fromentin, O. Hoegh-Guldberg, and F. Bairlein. 2002. Ecological responses to recent climate change. Nature 416:389-395.

Willig, M. R., D. M. Kaufman, and R. D. Stevens. 2003. Latitudinal gradients of biodiversity. Annual Review of Ecology and Systematics 34:273-309.

Wright, S. J. 1996. Phenological responses to seasonality in tropical forest plants. Pages 440-460 in S. S. Mulkey, R. L. Chazdon, and A. P. Smith, eds. Tropical forest plant ecophysiology. Chapman \& Hall, New York.

Wright, S. J., and C. P. van Schaik. 1994. Light and the phenology of tropical trees. American Naturalist 143:192-199.

Wright, S. J., O. Calderon, A. Hernandez, and S. Paton. 2004. Are lianas increasing in importance in tropical forests? a 17 -year record from Barro Colorado Island, Panama. Ecology 85:484-489.

Zotz, G., and K. Winter. 1996. Diel patterns of $\mathrm{CO}_{2}$ exchange in rainforest canopy plants. Pages 89-113 in S. S. Mulkey, R. L. Chazdon, and A. P. Smith, eds. Tropical forest plant ecophysiology. Chapman \& Hall, New York.

Associate Editor: Mark Westoby Editor: Jonathan B. Losos 